\title{
Pemrograman Rumah Sakit Jakarta
}

$\begin{array}{ll}\text { NPM } & : 19411085 \\ \text { NAMA } & \text { :Ricky Andrian Tomi } \\ \text { PRODI } & \text { :Sistem informasi } \\ \text { FAKULTAS } & \text { :Fakultas IImu Komputer } \\ \text { EMAIL } & \text { :rickyandrian295@gmail.com }\end{array}$

SOAL TUGAS :

1. Buatlah Program dengan ketentuan sebagai berikut:

Input :

kode pasien $=$ PSO003

Kode Kamar $=4444$

Lama Menginap $=5$ hari

Kode Dokter $=$ DK003

\begin{tabular}{|l|l|l|}
\hline Kode Pasien & Status Pasien & Biaya Daftar Pasien \\
\hline PS0001 & Pasien Baru & Rp. 500.000 \\
\hline PS0002 & Pasien Lama & Rp. 400.000 \\
\hline PS0003 & Pasien BPJS & Rp. 300.000 \\
\hline PS0004 & Pasien Askes & Rp. 200.000 \\
\hline
\end{tabular}

\begin{tabular}{|l|l|l|}
\hline Kode Kamar & Nama Kamar & Biaya Kamar \\
\hline 1111 & Kamar Melati & Rp. 1.000 .000 \\
\hline 2222 & Kamar Mawar & Rp. 2.000.000 \\
\hline 3333 & Kamar Dahlia & Rp. 3.000.000 \\
\hline 4444 & Kamar Anggrek & Rp. 4.000.000 \\
\hline 5555 & Kamar Tulip & Rp. 5.000.000 \\
\hline
\end{tabular}

\begin{tabular}{|l|l|}
\hline Lama Menginap & Diskon \\
\hline$>10$ Hari & $50 \%$ dari Biaya Kamar \\
\hline$>8$ Hari & $40 \%$ dari Biaya Kamar \\
\hline
\end{tabular}




\begin{tabular}{|c|c|c|}
\hline K6dkaEokter & NBaria DarkitiRiaya Kamar & Biaya Pemeriksaan \\
\hline DAKODY & D20 Anedtari Biaya Kamar & Rp. 500.000 \\
\hline BKD02 & DFo Iakkri Biaya Kamar & Rp. 400.000 \\
\hline DK003 & DR. Karni & Rp. 300.000 \\
\hline DK004 & DR. Amin & Rp. 200.000 \\
\hline DK005 & DR. Udin & Rp. 100.000 \\
\hline
\end{tabular}

Total Bayar $=$ Biaya Daftar Pasien + Biaya Kamar + Biaya Pemeriksaan - Diskon

Output (Tampilkan) $=$

Status Pasien

Biaya daftar Pasien

Nama Kamar

Biaya Kamar

Nama Dokter

Biaya Pemeriksaan

Diskon

Total Bayar 
SOURCE CODE / KODING PROGRAM (KETIK DIBAWAH INI)

public class TugasRicky\{

public static void main (String []args)\{

//deklarasi variabel

String kodepas="PS0003";

String kodedok = "DK003";

int kodekam = 4444;

String namadok,statuspas, namakam;

int durasi $=5$;

double discount;

int biayadaftr, total, biayakam, biayaprksa, totalkam;

//deklarasi proses

if (kodepas.equals("PS0001")) \{

statuspas = "Pasien Baru";

biayadaftr = 500000;

\} else if (kodepas.equals("PS0002"))\{

statuspas = "Pasien Lama";

biayadaftr $=400000$;

\} else if (kodepas.equals("PS0003"))\{

statuspas = "Pasien BPJS";

biayadaftr $=300000$;

\} else if (kodepas.equals("PS0004"))\{

statuspas = "Pasien Askes";

biayadaftr = 200000;

\} else \{

statuspas= "-";

biayadaftr $=0$;

if (kodekam $==1111)\{$

namakam = "Kamar Melati";

biayakam = 1000000;

\} else if (kodekam $==2222)\{$

namakam = "Kamar Mawar";

biayakam = 2000000;

\} else if (kodekam $==3333)$ \{

namakam = "Kamar Dahlia";

biayakam = 3000000;

\} else if (kodekam $==4444)\{$

namakam = "Kamar Anggrek";

biayakam = 4000000;

\} else if (kodekam $==5555)\{$

namakam = "Kamar Tulip"; 


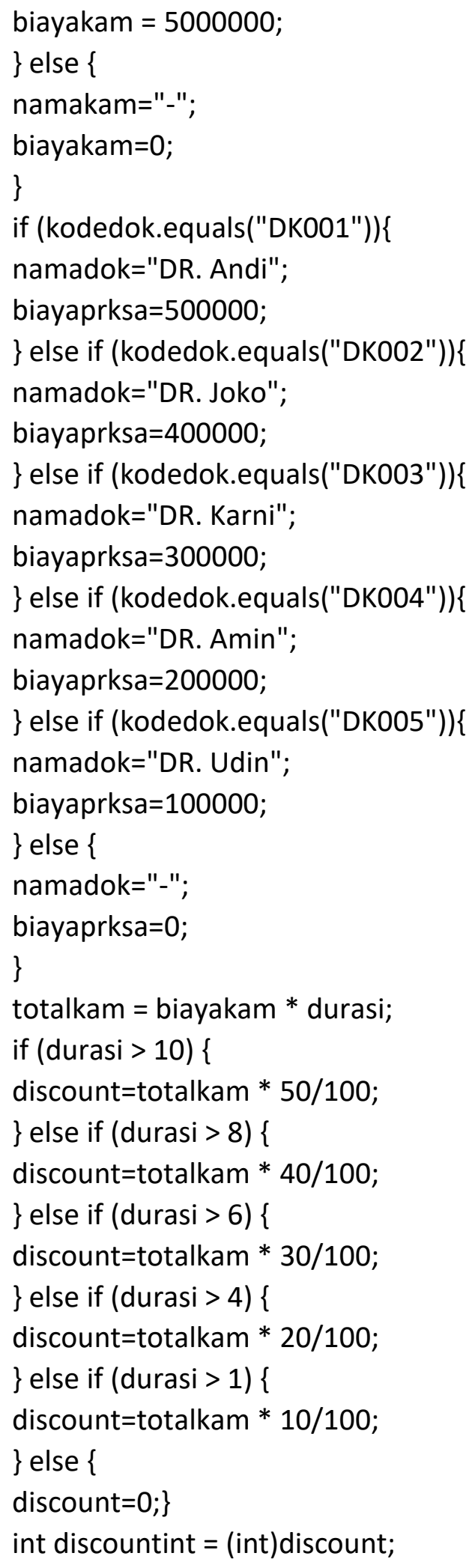


System.out.printIn("Nama Kamar : " +namakam);

System.out.printIn("Nama Dokter : " +namakam);

System.out.printIn("Total Biaya Periksa : " +biayaprksa);

System.out.printIn("Total Biaya Pendaftaran : " +totalkam);

System.out.printIn("Total Diskon : " +discount);

System.out.printIn("Total Bayar : " +total);

\}

\} 


\section{PENJELASAN SOURCE CODE (KETIK DIBAWAH INI)}

$\checkmark$ Public adalah kode akses yang bersifat umum.atau dalam artian bahwa kodingan tersebut dapat diakses oleh umum.

$\checkmark$ Class adalah cetakanuntuk menciptakan suatu instan dari object.

$\checkmark$ Biayarmhskt adalah nama dari class nya.

$\checkmark$ Static adalah salah satu jenis modifier di java yang digunakan agar suatu atribut ataupun method dapat diakses oleh kelas atau obejk tanpa harus melakukan instansiasi terhadap kelas tersebut.

$\checkmark$ Void adalah method yang tidak dimiliki nilai kembali,biasanya digunakan tidak untuk mencari nilai dalam suatu operasi.

$\checkmark$ main menerima sebuah argument arry bertipe string .

$\checkmark$ args tugas nya untuk menyimpan nilai argumen yang diberikan dari cmd atau terminal ,sehingga kita dapat mengolahnya dalam pemrograman.

$\checkmark$ if(kodePasien=="PS0001") untuk data disamping tidak akan terpanggil karena tidak sesuai dengan deklarasi variabel yang diberi nilai diatas atau yang saya beri garis bawah,

$\checkmark$ else if(kodePasien=="PS0003") untuk data disamping akan terpanggil karena sesuai dengan data diatas.

$\checkmark$ Buka tutup kurung kurawal\{\} dibawah if dan else if adalah data yang akan di tampilkan saat

$\checkmark$ yang di dalam kurung kurawal tersebut akan di tampilkan di System.out.println atau di cmd/terminal.

$\checkmark$ Untuk else berfungsi untuk mengakhiri if dan else if.

$\checkmark \quad$ “/proses

○ totalBayar= biayaDaftarPasien + biayaKamar + biayaPemeriksaan - Diskon;"

$\checkmark$ Lalu dibawah nya merupakan rumus yang akan kita hitung atau proses penghitungan.

$\checkmark$ Tambah(+),kurang(-),kali(*),bagi(/).

$\checkmark$ Untuk kodingan System.out.println berguna untuk menampilkan data yang akan kita tampilkan. pada tanda petik dua merupakan deskripsi yang akan muncul pada tampilan yang ada di cmd/terminal. Tanda + merupakan variabel yang akan dipanggil untuk di tampilkan di cmd/terminal.

$\checkmark$ Untuk tanda “; “ berguna untuk memberikan proses telah berakhir untuk satu baris pemrograman. 


\section{FLOWCHART PROGRAM}

\section{Start}

KODE PASIEN $=$ PSO03

KODE KAMAR $=4444$

LAMA MENGINAP =

5(HARI)

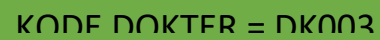

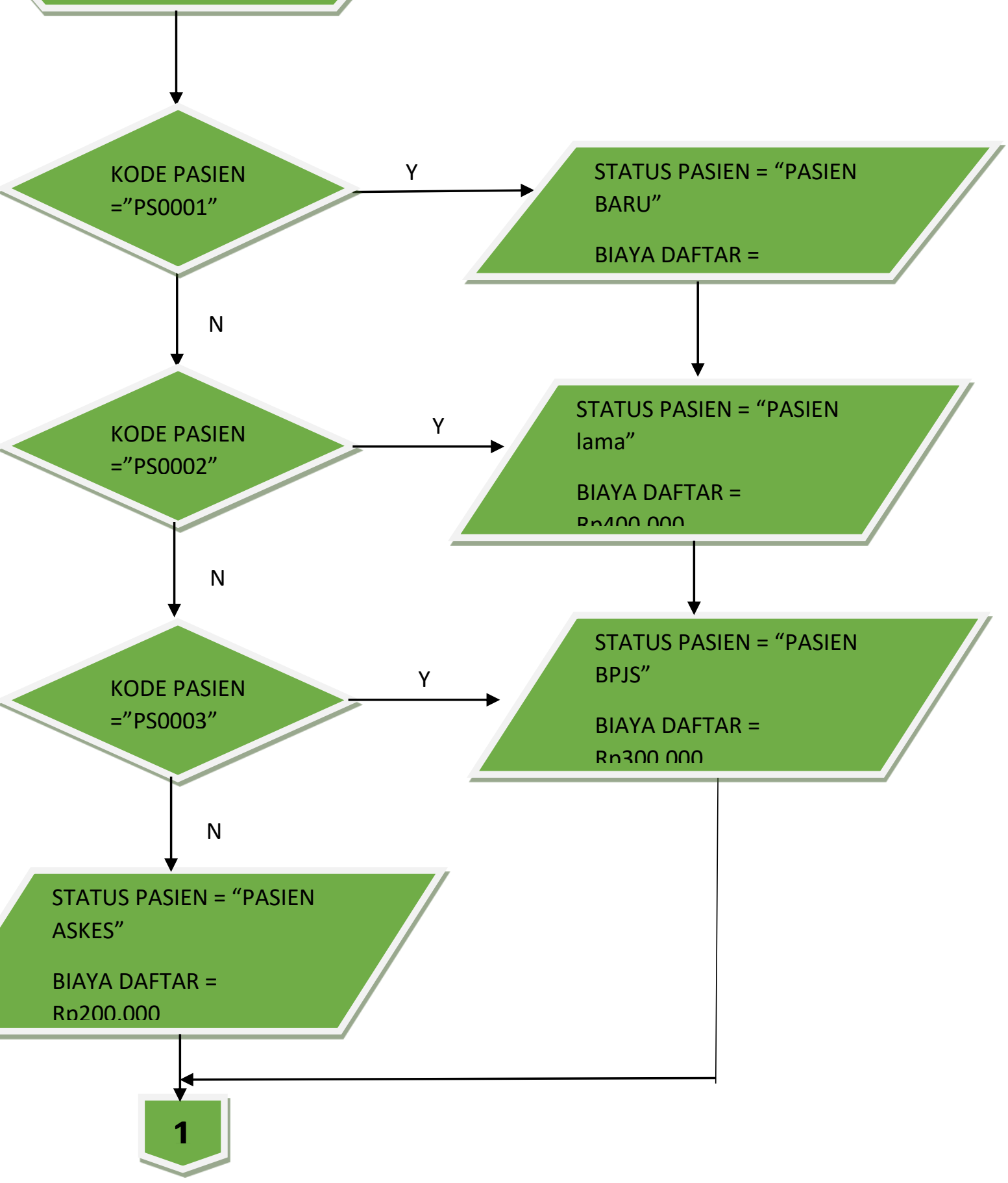




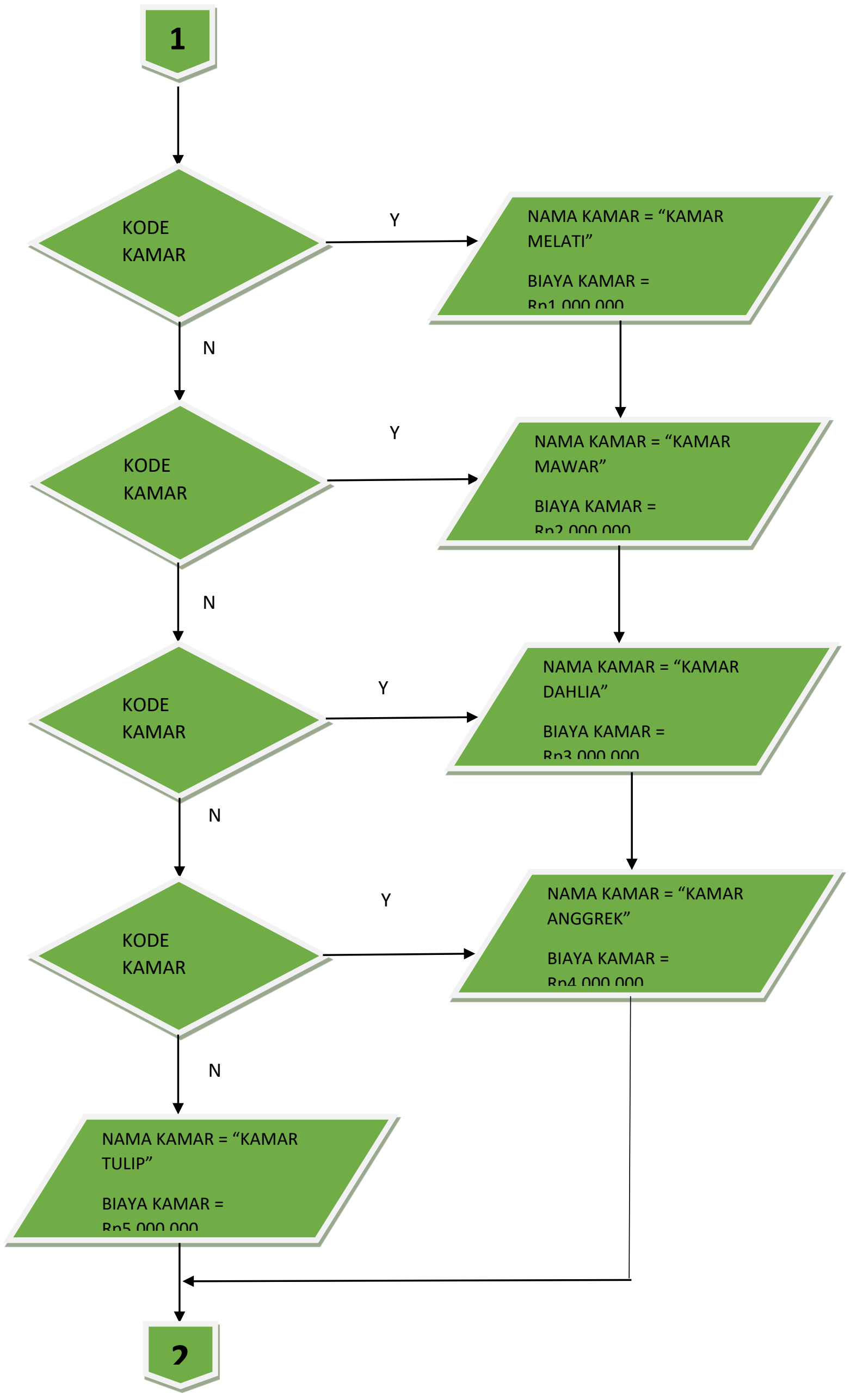




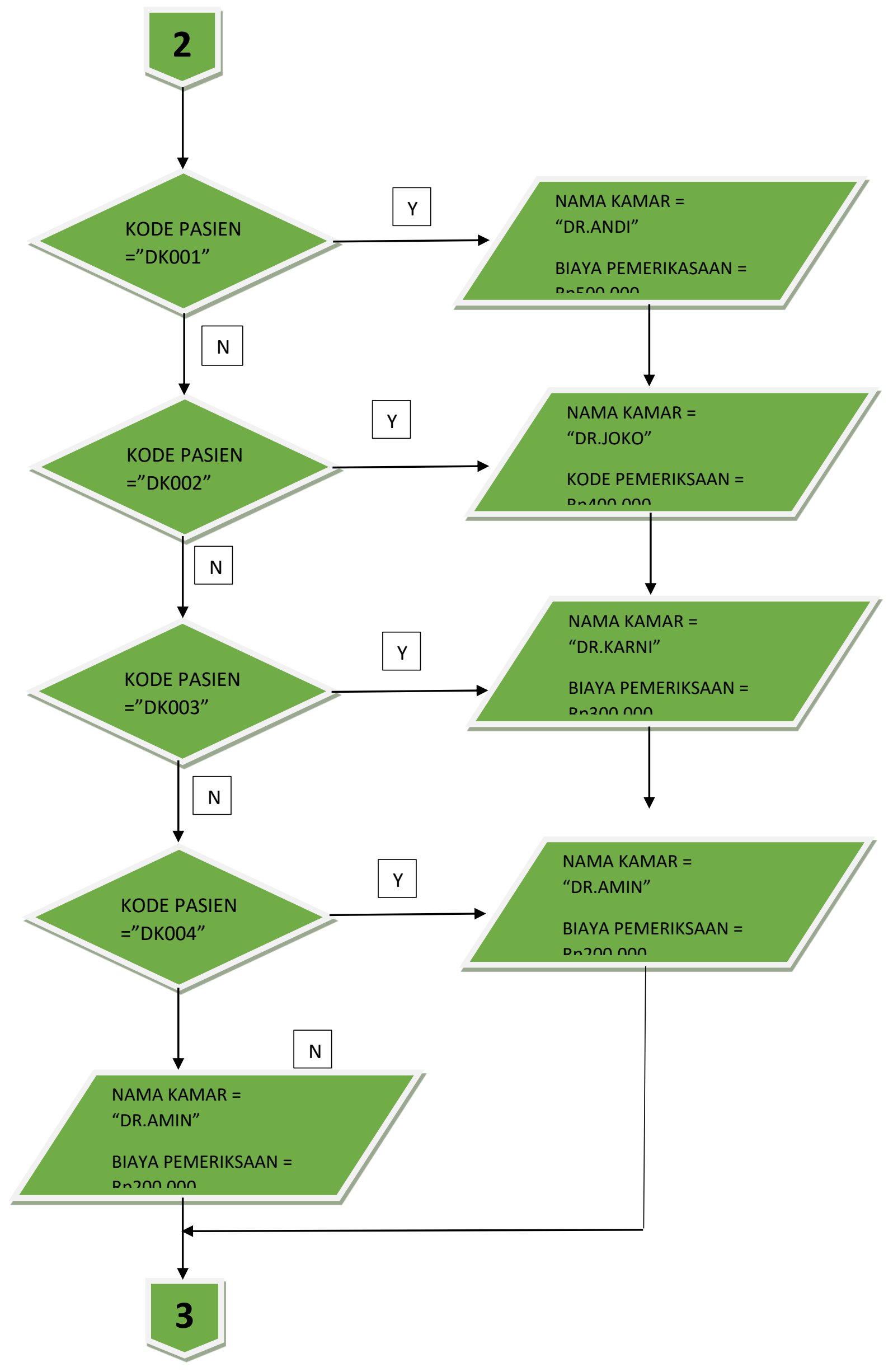




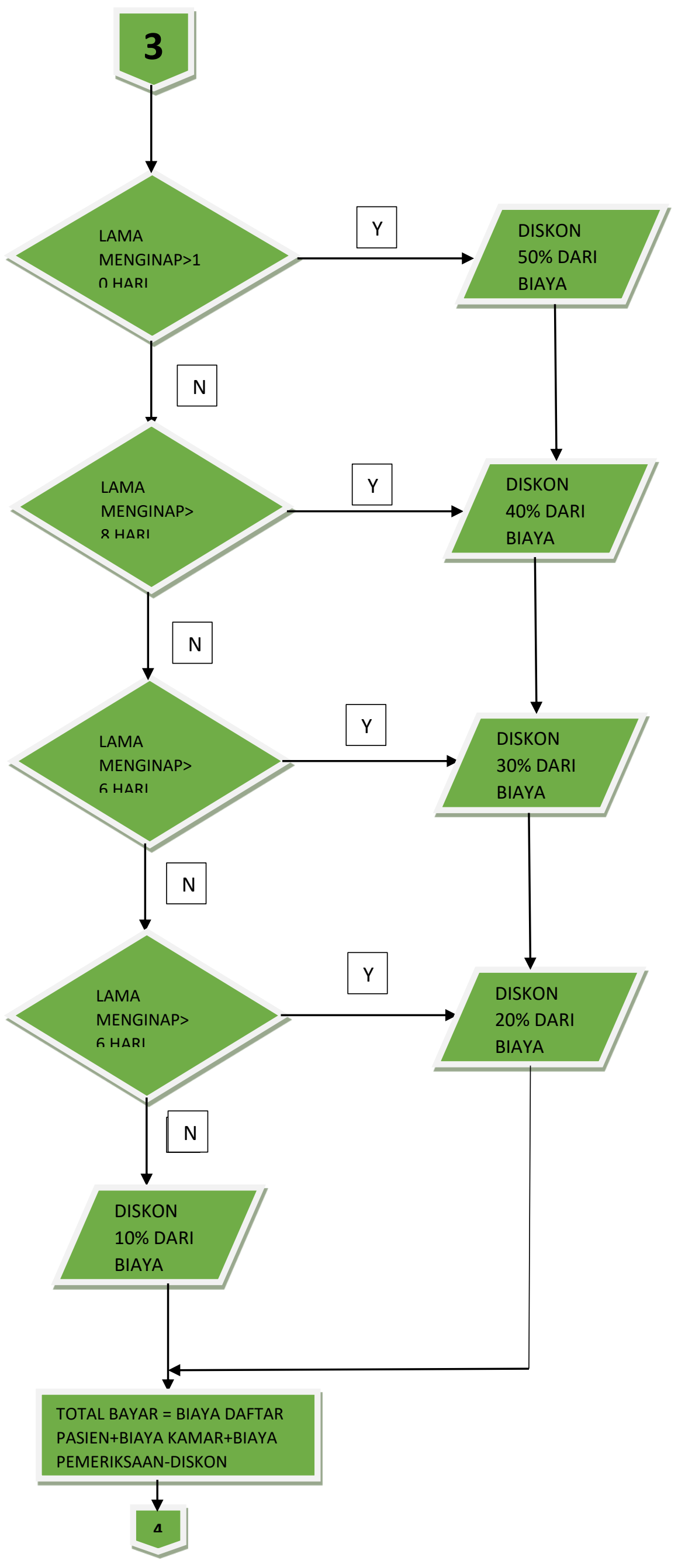




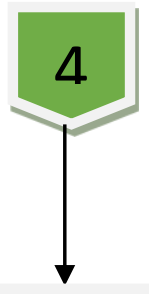

Status Pasien = "Pasien Baru"

Biaya daftar Pasien =

Rp.300.000

Nama Kamar = "Kamar Anggrek"

Biaya Kamar $=$ Rp.4.000.000

Nama Dokter = "Dr.Karni"

Biaya Pemeriksaan = Rp.300.000

Diskon $=$ Ro .800 .000

END 


\section{REFERENSI :}

Endra, R. Y. (2019, October 29). Belajar Mudah Algoritma dan Pemograman Java. Retrieved from osf.io/v7yfn

Endra, R. Y. (2019, October 29). Internet of Things. Retrieved from osf.io/4h8sf

\section{REFERENSI :}

Endra, R. Y. (2019, October 29). Belajar Mudah Algoritma dan Pemograman Java. Retrieved from osf.io/v7yfn

Endra, R. Y. (2019, October 29). Internet of Things. Retrieved from osf.io/4h8sf 